\title{
Effect of Flow Rates on erosion corrosion behavior of hull steel in real seawater
}

\author{
Jiangmin Xia ${ }^{1, *}$, Zhuying Li $^{1}$, Jingchao Jiang ${ }^{2}$, Xiaoqiang Wang ${ }^{1}$, Xiaodong Zhang ${ }^{1}$ \\ ${ }^{1}$ College of Naval Architecture \& Ocean Engineering, Naval University of Engineering, Wuhan \\ 430033, China \\ ${ }^{2}$ Department of Mechanical Engineering, University of Auckland, Auckland 1010, New Zealand \\ *E-mail: $\underline{x}$ jiangmin@163.com
}

doi: $10.20964 / 2021.05 .60$

Received: 20 January 2021 / Accepted: 11 March 2021 / Published: 31 March 2021

Currently, researches on erosion corrosion were mainly focused on laboratory or computer simulation based, which were more or less different from the real environment. And most of studies only paid attention to the initial changes in a short period of the erosion corrosion process, little attention had been paid to the variation of the whole test period. Most importantly, few articles can be found to study the critical flow rate of hull steel. Therefore, in this paper, the erosion corrosion of hull steel in different flow rates were comprehensively studied in a seawater (from East China Sea) environment. The critical flow velocity for hull steel material was obtained after the first analysis. The experiments of erosion corrosion behavior had been observed for 30 days, with seawater flow rates of $0,2,4$ and $6 \mathrm{~m} / \mathrm{s}$ in a selfdesigned rotary scouring test platform. In order to obtain good results, all the experiments had been last for more than 30 days. Electrochemical impedance spectroscopy (Hereinafter abbreviated to EIS), Electrochemical noise (Hereinafter abbreviated to EN) and Scanning Electron Microscope (Hereinafter abbreviated to SEM) method were used to analyze the process results and then comprehensively determined the critical flow velocity. The results showed that the higher the flow rate, the more complex the erosion corrosion reacted. During these 30 days, electrochemical corrosion rate rapidly increased, and then slowed down to a stable situation as time pass by. Among these results, the flow rate of $2 \mathrm{~m} / \mathrm{s}$ had the fastest electrochemical corrosion rate. Electrochemical noise average potential increased and the power spectral density (Hereinafter abbreviated to PSD) curve gradually diverges with the increase of the flow velocity, the $2 \mathrm{~m} / \mathrm{s}$ flow rate electrochemical noise potential standard deviation and the white noise level had the largest value and fluctuation. As the flow rate increased, double-layer corrosion products generated; the outer corrosion products became thinner and the inner layer of corrosion products gradually formed. The corrosion product morphology at static was similar to cauliflower, while the morphologies at $4 \mathrm{~m} / \mathrm{s}$ and $6 \mathrm{~m} / \mathrm{s}$ flow rate were net-like; and the morphology at $2 \mathrm{~m} / \mathrm{s}$ flow rate was in a situation between them. The critical synergy velocity of hull steel erosion in the East China Sea was $2 \mathrm{~m} / \mathrm{s}$ after comprehensive analysis. In the future, this critical flow rate should be considered as an important operation parameter, it was best for the ship and pipe to avoid running at this speed. 
Keywords: Erosion corrosion; Hull steel; Corrosion mechanism; Critical velocity.

\section{FULL TEXT}

(C) 2021 The Authors. Published by ESG (www.electrochemsci.org). This article is an open access article distributed under the terms and conditions of the Creative Commons Attribution license (http://creativecommons.org/licenses/by/4.0/). 